\title{
Change of seizure frequency in pregnant epileptic
} women

\author{
D. SCHMIDT, R. CANGER, $†$ G. AVANZINI, $\ddagger$ D. BATTINO, $\ddagger$ C. CUSI, \\ G. BECK-MANNAGETTA, S. KOCH, ${ }^{*}$ D. RATING, ${ }^{*}$ D. JANZ \\ From the Department of Neurology and Department of Pediatrics, ${ }^{*}$ Klinikum Charlottenburg, Free \\ University of Berlin, W-Germany; the Center for Epilepsy, $\dagger$ Psychiatric Clinic of the University of Milan; the \\ Institute of Neurology “ C. Besta”, $\ddagger$ Milan, Italy.
}

SUMMARY The effect of pregnancy on seizure frequency was monitored prospectively in 136 pregnancies of 122 epileptic women. Pregnancy did not influence the seizure frequency in 68 pregnancies $(50 \%)$. In 50 pregnancies $(37 \%)$ the number of seizures increased during pregnancy or puerperium. The seizure frequency decreased in 18 pregnancies (13\%). In 34 out of 50 pregnancies $(68 \%)$ the increase was associated with non-compliance with the drug regimen or sleep deprivation. In seven out of 18 pregnancies (39\%) improvement was related to correction of non-compliance or sleep deprivation during the pregestational nine months. Insufficiently low plasma concentrations of antiepileptic drugs were found in $47 \%$ of the women with uncontrolled epilepsy during pregnancy. The course of epilepsy during pregnancy is primarily influenced by non-compliance, sleep deprivation during pregnancy, and inadequate therapy before and during pregnancy. With good medical attention pregnancy itself seems to have only a minimal influence on the course of epilepsy.

Improvements in the drug therapy of epilepsy have led to a growing number of well controlled epileptic women in childbearing age. It is therefore not surprising that the influence of pregnancy on the course of epilepsy has received renewed interest. According to a recent review, the seizure frequency improved in $23 \%$ and deteriorated in another $24 \%$ of 2165 pregnancies. ${ }^{1}$ A number of variables may influence the seizure frequency. These include hormonal and metabolic factors, respiratory changes, psychological problems, non-compliance with the prescribed drugs regimen, changes in pharmocokinetics of antiepileptic drugs, and a modification of seizure propensity during pregnancy. ${ }^{1}$ Preliminary studies suggested that non-compliance, seizure provocation, and a decrease in the plasma concentration of antiepileptic drugs may be primarily involved in the regulation of seizure frequency during pregnancy. ${ }^{23}$ Changes in seizure propensity

Address for reprint requests: Priv.-Doz. Dr D. Schmidt, Abteilung für Neurologie, Klinikum Charlottenburg, Freie Universität Berlin, Spandauer Damm 130, 1000 Berlin 19, W Germany.

Received 27 September 1982 and in revised form 28 January 1983. Accepted 19 March 1983 can be studied directly in pregnant women not receiving antiepileptic drugs. The purpose of this prospective two-centre study of 136 pregnancies was to investigate changes in seizure frequency during pregnancy and to analyse clinical and pharmacological factors associated with a seizure relapse in the individual patient.

\section{Patients and Methods}

A total of 136 pregnancies of 122 epileptic women were followed prospectively from 1977 to 1981 in West-Berlin, Germany and Milan, Italy. Pregnant women were excluded from the study if they had a total of less than three verified epileptic seizures, the data on the seizure frequency were incomplete or the pregnancy was ended by abortion. The patients were referred to the Epilepsy Clinic in Milan and Berlin from departments of gynaecology and neurology and gynaecologists and neurologists for pregnancy planning and during early pregnancy. ${ }^{23}$ The project was made known to them by regular distribution of information in letters and reprints. The patients were evaluated neurologically and usually seen at monthly intervals, when the history of seizures was recorded. At each visit the patients were examined for clinical drug toxicity. Special emphasis was given to the history of the clinical factors possibly associated with an increase in seizure frequency or a relapse of seizures. The patients were asked specifically 
whether they had taken the daily dose regularly in the days before each individual seizure. Non-compliance was assumed only when the patient admitted to it. Furthermore, information was sought on seizure provocation by sleep deprivation, and consumption of ethanol, or both. Sleep deprivation was defined as a delay of more than 2 hours from the usual working day onset of sleep for the individual patient. Sleep deprivation was assumed to be a predisposing factor only in patients with a previous history of seizure provocation through sleep deprivation. At each visit the plasma concentration of phenytoin, phenobarbitone, carbamazepine, ethosuximide and valproic acid was measured in duplicate by enzyme immunoassay as described previously. ${ }^{4}$ For quality control the laboratories joined the European Quality Control Scheme organised by Prof A. Richens. ${ }^{5}$

One drug treatment was administered in 86 pregnancies $(63 \%)$ with carbamazepine $(n=12)$, primidone $(n=22)$, phenobarbitone $(n=20)$, phenytoin $(n=23)$, valproic acid $(n=4)$, ethosuximide $(n=3)$ or clobazam $(n=2)$. Two antiepileptic drugs were prescribed in 25 pregnancies and three drugs were given during two pregnancies. During 23 pregnancies the epileptic women did not take any antiepileptic drug. The clinical data of this series are given in table 1. For evaluation of the course of epilepsy, the

Table 1 Clinical features of the patients

\begin{tabular}{ll}
\hline Clinical data of the patients & \\
\hline No of patients & 122 \\
No of pregnancies & 136 \\
$\begin{array}{l}\text { Age at delivery } \\
\text { Generalised epilepsy }\end{array}$ & $25 \pm 4$ years \\
$\begin{array}{l}\text { Focal epilepsy } \\
\text { Duration of epilepsy }\end{array}$ & 62 \\
$\begin{array}{l}\text { No of patients with a total of less than seven } \\
\text { generalised tonic-clonic seizures }\end{array}$ & $13 \cdot 7 \pm 6$ years \\
$\begin{array}{l}\text { No of pregnancies with one or more seizure } \\
\text { types: }\end{array}$ & $42^{*}(39 \%)$ \\
$\begin{array}{l}\text { one type of seizures } \\
\text { two types of seizures } \\
\text { three types of seizures }\end{array}$ & 51 \\
\hline
\end{tabular}

*No information in six patients, no generalised tonic-clonic seizures in nine patients, resulting in 107 patients. number and type of seizure was compared in each patient during the nine months before pregnancy and during each trimester of pregnancy. We also analysed changes in seizure frequency during the puerperium that is the three months following the delivery. Fifty-three patients were followed up to the 12 th month following the pregnancy. Increase or decrease of seizure frequency was defined by giving the actual seizure frequency. Percentages alone were considered inadequate as a means of defining change.

\section{Results}

Pregnancy did not influence the seizure frequency in 68 pregnancies $(50 \%)$. In 38 of the 68 pregnancies the epileptic women had had no seizures in the pregestational nine months and during pregnancy. In 50 pregnancies $(37 \%)$ the number of seizures increased during pregnancy or puerperium. Finally, the number of seizures decreased during pregnancy in 18 pregnancies $(13 \%)$.

\section{Increased seizure frequency}

The number of seizures increased in 50 pregnancies (table 2). Non-compliance or sleep deprivation were noted in a temporal relationship to a seizure relapse in 34 out of 50 pregnancies $(68 \%)$. Except for a higher incidence of generalised epilepsy as compared to focal epilepsy $(59 \%$ vs. $13 \%)(p=0.02)$, the non-compliers did not differ in clinical characteristics from the other patients. Non-compliance or sleep deprivation were implicated in 27 out of 34 pregnancies $(79 \%)$ with an increase of generalised tonic-clonic seizures and in five out of 12 pregnancies $(42 \%)$ with increased simple or complex-partial seizures. In 29 pregnancies $(58 \%)$ the increase was first seen during the first trimester (fig 1). The increase in seizure frequency during puerperium was related to non-compliance or sleep deprivation in five of six pregnancies.

Table 2 Type of seizures, non-compliance and sleep deprivation in pregnancies with increased seizure frequency

\begin{tabular}{|c|c|c|c|c|c|c|c|}
\hline \multirow[b]{2}{*}{ Type of seizures } & \multicolumn{7}{|c|}{ No. of pregnancies with increased seizure frequency } \\
\hline & Total & $N C-S D$ & $\begin{array}{l}\text { No } \\
\text { bef } \\
\text { pre }\end{array}$ & $e^{\cdot} N C-S D$ & $\begin{array}{l}\text { Seizures } \\
\text { before } \\
\text { pregnancy }\end{array}$ & $N C-S D$ & $\begin{array}{l}\text { Percent increase } \\
\text { in seizures* } \\
\text { (mean and range) }\end{array}$ \\
\hline \multirow[t]{2}{*}{$\begin{array}{l}\text { GTC alone } \\
\text { GTC and CPS } \\
\text { GTC and SPS } \\
\text { CPS or SPS } \\
\text { Absence }\end{array}$} & $\begin{array}{r}34 \\
1 \\
1 \\
12 \\
2\end{array}$ & $\begin{array}{r}27 \\
1 \\
0 \\
5 \\
1\end{array}$ & $\begin{array}{r}15 \\
0 \\
1 \\
7 \\
0\end{array}$ & $\begin{array}{r}14 \\
0 \\
0 \\
4 \\
0\end{array}$ & $\begin{array}{r}19 \\
1 \\
0 \\
5 \\
2\end{array}$ & $\begin{array}{r}13 \\
1 \\
0 \\
1 \\
1\end{array}$ & $\begin{array}{l}+233 \%(100-400)(8)^{\mathrm{a}} \\
+100 \text { and } 200 \%(1)^{\mathrm{b}} \\
+270 \%(255-300)(3)^{\mathrm{c}} \\
\text { nd }(2)\end{array}$ \\
\hline & 50 & 34 & 23 & 18 & 27 & 16 & \\
\hline
\end{tabular}

GTC = generalised tonic-clonic seizures; CPS = complex-partial seizures; SPS = simple partial seizures; NC = non-compliance in 15 women; $\mathrm{SD}=$ sleep deprivation in 14 women, and both, $\mathrm{NC}$ and $\mathrm{SD}$, in 1 woman; ${ }^{*}=$ No of patients with this type of seizure in the nine months before pregnancy; nd = not determined as quantification of absence seizures was difficult.

Actual seizure frequency of the individual patient in the nine months before and during pregnancy:

$\mathrm{a}=$ GTC: 1 vs. 2,1 vs. 3,1 vs. 4,9 vs. 44,5 vs. 12,17 vs. 40,4 vs. 20,9 vs. 20

b = GTC: 2 vs. 4 and 1 vs. 3 cps.

c $=$ cps: 2 vs. 8,11 vs. 39,9 vs. 32 


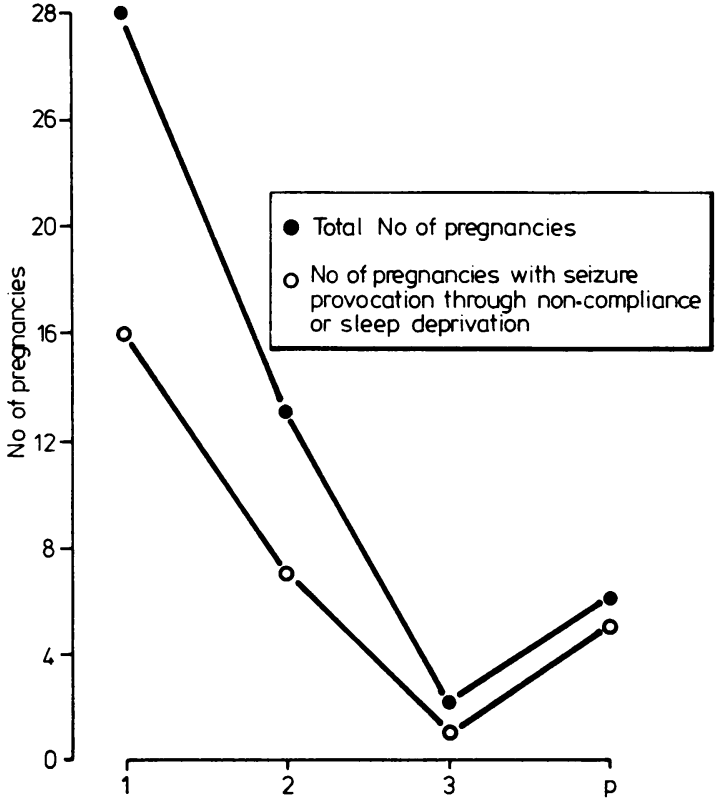

Fig 1 The onset of increased seizure frequency in the three trimesters of pregnancy $(1,2,3)$, and during puerperium (p). The figure shows that in most pregnancies the increase begins in the furst trimester, while it is lowest in the third trimester. Non-compliance and sleep deprivation account for 5 out of 6 pregnancies (83\%) with increased seizure frequency during puerperium.

The rate of increase varied widely. Thirteen out of 23 patients who were completely free of seizures in the nine months before pregnancy developed a single generalised tonic-clonic seizure and two patients had more than one generalised tonic-clonic seizure. Seven patients had three to six simple or one to three complex-partial seizures, and one patient had a single generalised tonic-clonic seizure and simple focal seizures. Among the 27 patients who were uncontrolled in the nine months before pregnancy, 13 patients developed either one to three generalised tonic-clonic seizures or two complex-partial seizures which they did not have in the nine months before pregnancy. In the other 14 patients, the average increase in percent was $223 \%$ for generalised tonic-clonic seizures and $270 \%$ for simple or complex-partial seizures (table 2).

Antiepileptic drug monitoring could be evaluated in 11 out of 16 pregnancies in which noncompliance or sleep deprivation was not involved in seizure precipitation. In nine pregnancies of women with previously uncontrolled epilepsy the plasma concentration was not increased or fluctuated widely during pregnancy. In one pregnancy a decrease in plasma concentration was not associated with an increased seizure frequency, while only in one out of 11 pregnancies the number of seizures increased despite a higher plasma concentration.

\section{Decreased seizure frequency}

The pregnancy seemed to have a beneficial effect on seizure frequency in 18 pregnancies. The number of seizures decreased by $50 \%(23 \%-70 \%)$ in seven patients, and 11 patients became completely controlled during pregnancy. In seven women noncompliance or sleep deprivation was associated with seizures in the pregestational nine months, while the women remained free of seizures during pregnancy. In four out of the remaining 11 pregnancies the plasma concentration was increased or a new drug

Table 3 Clinical features in relation to different courses of epilepsy during pregnancy

\begin{tabular}{|c|c|c|c|c|c|c|}
\hline \multirow[t]{2}{*}{ Clinical features } & \multicolumn{6}{|c|}{ Change in seizure frequency during pregnancy } \\
\hline & $\begin{array}{l}\text { No change } \\
n\end{array}$ & $\underset{\%}{(n=68)}$ & $\begin{array}{l}\text { Increase } \\
n\end{array}$ & $\underset{\%}{(n=50)}$ & $\underset{n}{\text { Decrease }}$ & $\underset{\%}{(n=18) \|}$ \\
\hline \multirow{3}{*}{$\begin{array}{l}\text { Age at the delivery } \geqslant 28 \text { years } \\
\text { Primary generalised epilepsy } \\
\text { Focal epilepsy } \\
\text { One type of seizures } \\
\text { Two types of seizures } \\
\text { Three types of seizures } \\
\text { Duration of epilepsy } \geqslant 10 \text { years } \\
\text { No generalised tonic-clonic seizure } \\
\text { in the year before pregnancy } \\
\text { Total or less than seven generalised } \\
\text { tonic-clonic seizures } \\
\text { Family history of epilepsy }\end{array}$} & $\begin{array}{c}7 \\
42^{*} \\
26 \dagger \\
28 \ddagger \\
36 \\
4 \\
44\end{array}$ & $\begin{array}{r}10 \\
62 \\
38 \\
41 \\
53 \\
6 \\
65\end{array}$ & $\begin{array}{l}13 \\
22^{*} \\
28 \dagger \\
14 \ddagger \\
33 \\
3 \\
35\end{array}$ & $\begin{array}{r}26 \\
44 \\
56 \\
28 \\
66 \\
6 \\
70\end{array}$ & $\begin{array}{r}6 \\
10 \\
8 \\
9 \\
7 \\
2 \\
11\end{array}$ & $\begin{array}{l}33 \\
56 \\
44 \\
50 \\
39 \\
11 \\
71\end{array}$ \\
\hline & $49 \S$ & 72 & 26 & 52 & $6 \S$ & 33 \\
\hline & $\begin{array}{r}28 \\
6\end{array}$ & $\begin{array}{r}41 \\
9\end{array}$ & $\begin{array}{r}17 \\
8\end{array}$ & $\begin{array}{l}34 \\
16\end{array}$ & $\begin{array}{l}4 \\
3\end{array}$ & $\begin{array}{l}22 \\
17\end{array}$ \\
\hline
\end{tabular}


was introduced during pregnancy. In five pregnancies the plasma concentration remained unchanged during pregnancy. During two pregnancies no drug therapy was given.

We found no clinical features which help to predict an increase or a decrease of seizure frequency in the individual patient (table 3). Primary generalised epilepsy, patients with only one type of seizure and no generalised tonic-clonic seizure in the year before pregnancy were fewer in the group with an increase in seizure frequency. The difference did not reach statistical significance of $p<0.05$, however (table 3).

In 53 pregnancies the number of seizures was compared from nine months before to 12 months following the pregnancy. In 34 pregnancies $(64 \%)$ a similar number of seizures or absence of seizures was recorded in the pregestational nine months and during months 4 to 12 following the delivery. In 17 pregnancies the seizures returned to the pregestational frequency after an increase or a decrease during pregnancy. In 19 pregnancies the number of seizures was lower $(n=17)$ during the pregestational period, and only rarely higher $(n=2)$.

The course of epilepsy was studied during 23 pregnancies without antiepileptic drug therapy. There was no change in seizure frequency in 13 out of 23 pregnancies $(57 \%)$. In eight pregnancies $(35 \%)$ the number of seizures increased. Sleep deprivation was responsible in six of eight pregnancies. In two pregnancies $(9 \%)$ the number of seizures improved. When compared to the changes in seizure frequency in women receiving drug treatment there was no significant difference.

The first antiepileptic drug plasma concentration obtained during pregnancy was either below 10 $\mu \mathrm{g} / \mathrm{ml}$ phenytoin, or $25 \mu \mathrm{g} / \mathrm{ml}$ phenobarbitone 4 $\mu \mathrm{g} / \mathrm{ml}$ carbamazepine or $50 \mu \mathrm{g} / \mathrm{ml}$ ethosuximide and valproic acid in $63 \%$ of all 98 pregnancies despite uncontrolled seizure before $(n=75)$ or during $(n=23)$ pregnancy. The highest plasma concentrations of antiepileptic drugs during pregnancy were still below this range in $47 \%$ of the patients with uncontrolled epilepsy.

\section{Discussion}

Pregnancy had either no or a beneficial influence on the seizure frequency in nearly two-thirds of all pregnancies. In 50 pregnancies $(37 \%)$ the number of seizures increased during pregnancy. This overall result is similar to that of prospective studies in Finland $^{6}$ and Canada, ${ }^{7}$ and retrospective reports. ${ }^{8-10}$

A discussion of the factors responsible for a change in the course of epilepsy must consider the random fluctuations of seizure frequency observed during a 18 months period in any patient regardless of pregnancy, and try to establish factors specific for the pregnant epileptic women which could possibly influence the course of epilepsy. At the onset of pregnancy the seizures were uncontrolled in 75 pregnancies $(55 \%)$ suggesting less than optimal drug treatment prior to the pregnancy if one accepts that complete seizure control can be achieved in $70-80 \%$ of the patients with adequate drug therapy. ${ }^{11}$ This is supported by the finding that $63 \%$ of these women were treated with inadequately low plasma concentrations of antiepileptic drugs. The highest plasma concentrations of antiepileptic drugs during pregnancy were still below the accepted therapeutic range in $47 \%$ of the pregnant women with uncontrolled epilepsy.

One mechanism for a reduction of the seizure frequency during pregnancy was the improvement of inadequate therapy prior to the pregnancy or the correction of non-compliance and sleep deprivation in 11 of 18 pregnancies $(61 \%)$. In seven pregnancies the improvement of seizure frequency cannot be explained and may be due to random fluctuation of seizure frequency or other factors (for example hormonal changes). The finding that an improved drug treatment, and not the pregnancy itself, may be responsible for a reduction of seizures suggests that the reverse mechanism may be partly responsible for a deteriorated course of epilepsy during pregnancy. In fact, in 34 out of 50 pregnancies $(68 \%)$ admitted non-compliance with the prescribed drug regimen or sleep deprivation were associated with an increase in seizure frequency. This preventable mechanism of seizure provocation is therefore a previously underestimated major factor which determines the course of epilepsy in pregnancy. Non-compliance or sleep deprivation may be suspected in a woman with generalised epilepsy, a single relapse of mostly generalised tonic-clonic seizures, and a history of non-compliance or seizure provocation through sleep deprivation. Non-compliance with the drug regimen is most frequent at the onset of pregnancy, usually when the woman finds out that she is pregnant. Fear of malformations or other adverse effects of antiepileptic drugs are given by a number of women as the motivation to stop the treatment. Unfortunately, some physicians supported the women in their intent to reduce or stop the drug treatment, possibly because of the impression that the teratogenetic risk increases with a higher dose of the antiepileptic drug. Currently, there is no evidence to support this impression. ${ }^{12}$

Of further concern is the finding that the relapse of seizures during the puerperium is associated with either an insufficient drug therapy, that is the patient does not receive her daily dose because the obstetri- 
cian is unaware of her drug treatment or someone has simply forgotten to give her the drug in the hospital. Additional sleep deprivation which may occur throughout during the pregnancy, is characteristically associated with a relapse of seizure during breast feeding in the puerperium. Care should be taken that the mother has her regular hours of sleep, possibly through the help of the husband or a relative who takes care of the child at night. In 16 out of the 50 pregnancies with increased seizure frequency non-compliance or sleep deprivation were not involved according to the patient's history. In nine of these pregnancies the drug treatment was not sufficient to increase the steady-state plasma concentration above those during pregestational period where the patients were uncontrolled. In one pregnancy the seizure frequency increased despite higher plasma concentration during pregnancy. Consequently, the increase in seizure frequency remains unexplained in six pregnancies and may entirely reflect the spontaneous course of chronic epilepsies during a period of 18 months regardless of pregnancy. Furthermore, sleep deprivation was responsible for the increased seizure frequency in six of eight pregnancies of women not taking antiepileptic drugs indicating that it is a major factor for the deterioration of untreated epilepsies. In this series clinical data other than those related to noncompliance and sleep deprivation were not helpful to predict the individual's course of epilepsy during pregnancy. We could not confirm the value of the pre-pregnancy frequency of generalised tonic-clonic seizures, the duration of epilepsy, and the course of epilepsy in previous pregnancies as suggested by Remillard et al. ' This report is in agreement with the large Finnish series of Bardy ${ }^{6}$ who likewise found no clinical factors which predict the increase in the number of seizures. The clinical implication of our data for the management of the pregnant epileptic woman suggest that a renewed effect should be made to completely control the epilepsy with the help of adequate drug therapy when pregnancy is planned. Specific risks include the discontinuation or reduction of drug therapy especially during early pregnancy, deficient drug delivery in the obstetric department, and seizure provocation through sleep deprivation during pregnancy and breast feeding.

In conclusion then, pregnancy itself does seem to have only a minimal effect on the course of epilepsy, if at all. In the few patients with an unexplained increase of seizure frequency the influence of other factors (e.g. hormonal, random fluctuations of seizure frequency) remains to be evaluated.

\section{References}

${ }^{1}$ Schmidt D. The effect of pregnancy on the natural history of epilepsy: review of the literature. In: Janz D, Dam M, Richens A, Bossi L, Helge H, Schmidt D, eds. Epilepsy, Pregnancy, and the Child. New York: Raven Press, 1982:3-14.

${ }^{2}$ Canger R, Avanzini G, Battino D, Bossi L, Franceschetti S, Spina S. Modifications of seizure frequency in pregnant patients with epilepsy: a prospective study. In: Janz D, Dam M, Richens A, Bossi L, Helge H, Schmidt D, eds. Epilepsy, Pregnancy, and the Child. New York: Raven Press, 1982:33-8.

${ }^{3}$ Schmidt D, Beck-Mannagetta G, Janz D, Koch S. The effect of pregnancy on the course of epilepsy: a prospective study. In: Janz D, Dam M, Richens A, Bossi L, Helge H, Schmidt D, eds. Epilepsy, Pregnancy, and the Child. New York: Raven Press, 1982:39-49.

${ }^{4}$ Schmidt D, Kupferberg HJ. Diphenylhydantoin, phenobarbital and primidone in saliva, plasma and cerebrospinal fluid. Epilepsia 1975;16:735-41.

${ }^{5}$ Richens A. Results of a phenytoin quality control scheme. In: Schneider H, Janz D, Gardner-Thorpe C, Meinardi H, Sherwin AL, eds. Clinical Pharmacology of Antiepileptic Drugs. Heidelberg: Springer Verlag, 1975:293-303.

${ }^{6}$ Bardy AH. Seizure frequency in epileptic women during pregnancy and puerperium: results of the prospective Helsinki study. In: Janz D, Dam M, Richens A, Bossi L, Helge H, Schmidt D, eds. Epilepsy, Pregnancy, and the Child. New York: Raven Press, 1982:27-31.

${ }^{7}$ Remillard G, Dansky L, Andermann E, Andermann F. Seizure frequency during pregnancy and the puerperium. In: Janz D, Dam M, Richens A, Bossi L, Helge H, Schmidt D, eds. Epilepsy, Pregnancy, and the Child. New York: Raven Press, 1982:15-26.

${ }^{8}$ Dam M, Christiansen J, Munck O, Mygind KI. Antiepileptic drugs: Metabolism in pregnancy. Clin Pharmacokin 1979;4:53-62.

${ }^{9}$ Mauranges P. Le mariage des épileptiques. Sem Med Prof Med Soc 1966;42:221-223.

${ }^{10}$ Deblay MF. L'enfant de mère epileptique. Thesis, Université de Nancy I 1978.

"Reynolds EH, Shorvon SD. Monotherapy or polytherapy for epilepsy? Epilepsia 1981;22:1-10.

12 Janz D. On major malformations and minor anomalies in the offspring of parents with epilepsy: review of the literature. In: Janz D, Dam M, Richens A, Bossi L, Helge H, Schmidt D, eds. Epilepsy, Pregnancy, and the Child. New York: Raven Press, 1982:211-22. 